\title{
Pengaruh Lama Perendaman dalam Larutan Kimia Terhadap Sifat Dormansi Biji Aren (Arenga pinnata Wurmb Merr)
}

\author{
Farida $^{1}$ \\ ${ }^{1}$ Dosen Program Studi Agroteknologi, Sekolah Tinggi Pertanian Kutai Timur \\ Jl. Soekarno-Hatta No. 1 Sangatta, Kutai Timur \\ Email : faridaihsan31@gmail.com
}

\begin{abstract}
The purpose of this research wa to know the effect of chemical solution submersion of sugar palm seed to its germination capability. Experiment were hold in Sangatta, East Kutai on September - November 2017 period. The experiments was conducted in non factorial experiments on Completely Randominazed Design (CRD) with four replications. The Submersion treatment were $p 0=$ no seed soaked, $p 1=5$ minutes of seed soaked, $p 2=10$ minutes of seed soaked, $p 3=$ minutes of seed soaked, $p 4=20$ minutes of seed soaked, $p 5=25$ minutes of seed soaked. The result showed that the submersion treatment was highly significatly at 36 days germination period, germination percentage was $78.33 \%$, and index vigor was 0.161 .
\end{abstract}

Keyword : Aren, Chemstry, Dormansi.

\section{ABSTRAK}

Tujuan penelitian ini adalah untuk mengetahui pengaruh lama perendaman dalam larutan kimia yang terbaik terhadap perkecambahan biji Aren. Penelitian ini akan dilaksanakan pada bulan September - November 2017. Lokasi penelitian bertempat di Desa Swarga Bara Sangatta Kutai Timur. Penelitian menggunakan Rancangan Acak Lengkap (RAL) non faktorial di ulang sebanyak 4 kali. Adapun perlakuan perendaman, yaitu: $\mathrm{p} 0=$ tanpa perendaman (kontrol), $\mathrm{p} 1=$ perendaman 5 menit, $\mathrm{p} 2=$ perendaman 10 menit, $\mathrm{p} 3=$ perendaman 15 menit, $\mathrm{p} 4=$ perendaman 20 menit, $\mathrm{p} 5=$ perendaman 25 menit. Hasil penelitian menunjukkan bahwa Perlakuan $p_{4}$ (perendaman selama 20 menit) yang terbaik pada laju perkecambahan sebesar 36,00 hari, persentase perkecambahan sebesar $78,33 \%$ dan indeks vigor sebesar 0,161 .

Kata Kunci: Aren, Larutan Kimia, Dormansi

\section{Pendahuluan}

Aren (Arenga pinnata Merr) merupakan tanaman yang termasuk dalam family palm, dimana hampir seluruh bagian tanamannya dapat dimanfaatkan dan memiliki nilai ekonomi. Tanaman Aren (Arenga pinnata Merr) perlu dikembangkan karena kegunaanya cukup banyak. Dalam rangka menunjang program pengembangan tanaman tanaman Aren, ketersediaan benih merupakan salah satu faktor yang sangat penting. Benih Aren memerlukan waktu relatif lama untuk perkecambahanya karena memiliki struktur kulit yang tebal dan keras. Pada kondisi alami benih baru bisa berkecambah 6-24 bulan setelah semai (Mashud, Rahman dan Malangakay,1989).

Aren (Arenga pinnata Merr) memiliki kulit biji yang keras sehingga untuk memacu proses perkecambahan perlu dilakukan perlakuan pematahan dormansi. Perlakuan kimia yang diberikan pada benih yang dorman khususnya yang disebabkan kulit benih menjadi lunak dan mudah dimasuki air dan udara., Bahan kimia dapat digunakan sebagai perlakuan untuk memecahkan dormansi pada benih. Tujuannya adalah menjadikan agar kulit biji lebih 
mudah dimasuki oleh air pada waktu proses imbibisi. Bahan kimia yang sering digunakan antara lain adalah auksin (Sutopo, 2012).

Lamanya perlakuan perendaman dalam larutan kimia juga menjadi faktor penentu dalam perkecambahan benih Aren. Lamanya perendaman harus memperhatikan 2 hal yaitu: 1) kulit biji atau pericarp yang dapat diretakkan untuk memungkinkan imbibisi, 2) larutan asam tidak mengenai embrio (Lakitan, 2007). Penelitian sebelumnya (Farida,2017) menyatakan bahwa perendaman dalam giberelin $\left(\mathrm{GA}_{3}\right)$ dengan lama perendaman 20 menit menunjukkan persentase berkecambah (82,50\%), kecepatan berkecambah (46,76 hari) dan indeks vigor $(0,158)$ yang terbaik dibandingkan dengan perlakuan lainnya. Berdasarkan uraian diatas, maka perlu dilakukan penelitian tentang "uji efektivitas lama perendaman dalam larutan kimia terhadap sifat dormansi biji Aren (Arenga pinnata Wurmb Merr)".

Tujuan penelitian ini adalah mengetahui pengaruh lama perendaman dalam larutan auksin yang terbaik terhadap perkecambahan biji aren.

\section{Metode Penelitian}

Penelitian akan dilaksanakan pada bulan September - November 2017. Lokasi penelitian bertempat di Desa Swarga Bara Sangatta Kutai Timur. Bahan yang digunakan yaitu biji Aren varietas genjah, auksin, pasir, arang sekam dan air. Sedangkan alat yang akan digunakan adalah meteran, gembor, bak semai, kamera, dan alat tulis.

Penelitian ini merupakan penelitian non factorial yang disusun dalam Rancangan Acak Lengkap (RAL) dengan 6 taraf perendaman dan masing-masing perlakuan di ulang sebanyak 4 kali. Adapun perlakuan perendaman $(\mathrm{P})$, yaitu: $\mathrm{p} 0=$ tanpa perendaman (kontrol), p1 = perendaman 5 menit, p2 = perendaman 10 menit, p3 = perendaman 15 menit, p4 = perendaman 20 menit, p5 = perendaman 25 menit.

\section{Persiapan biji}

Benih diambil dari pohon yang memenuhi syarat sebagai pohon induk, kemudian dipilih buah yang telah masak fisiologi dengan ciri-ciri berwarna kuning kecoklatan. Pisahkan biji dengan kulit buah dengan menggunakan sarung tangan. Untuk menentukan benih yang baik yaitu dengan cara biji aren dimasukkan kedalam air, biji yang tenggelam merupakan biji yang akan digunakan sebagai benih, sedangkan biji yang mengapung merupakan biji yang tidak layak digunakan. Benih yang terpilih selanjutnya direndam dalam larutan Dithane-45 selama 10 menit agar bebas dari mikroorganisme yang merugikan. Setiap perlakuan dibutuhkan 20 biji sehingga ada 480 biji Aren.

\section{Perendaman dalam larutan auksin}

Benih aren direndam dalam air panas selama 30 menit, kemudian direndam dalam larutan atonik dengan konsentrasi 100 ppm. Lama perendaman dalam larutan atonik 
disesuaikan dengan perlakuan yang digunakan. Selanjutnya benih disaring dan dikering anginkan.

\section{Persiapan media kecambah}

Media perkecambahan yang digunakan dalam penelitian ini yaitu pasir dan arang sekam dengan perbandingan 1:1. Sebelum media pasir digunakan, terlebih dahulu disterilkan dengan menyangrai pasir pada suhu $70^{\circ} \mathrm{C}$ selama 15 menit. Hal ini bertujuan agar media pasir yang akan digunakan terhindar dari mikroorganisme.

\section{Penanaman dalam bak semai}

Benih aren yang telah diberikan perlakuan siap ditanam dalam bak semai dengan jarak $5 \mathrm{~cm}$ antar benih. Dengan bagian mata tunas menghadap ke atas.

Parameter pengamatan adalah sebagai berikut:

a. Laju Perkecambahan

Laju perkecambahan dihitung dengan menghitung dari waktu munculnya plumula benih dari awal berkecambah sampai akhir. Menurut Sutopo (2012) cara untuk menghitung laju perkecambahan adalah sebagai berikut:

$$
L P=\frac{N_{1} T_{1}+N_{2} T_{2}+N_{3} T_{3} \ldots+N_{x} T_{x}}{\sum \text { seluruh benih yang berkecambah }}
$$

Keterangan:

LP $\quad=$ Laju perkecambahan

$\mathrm{N} \quad=$ Jumlah benih yang berkecambah setiap hari

$\mathrm{T}=$ Jumlah waktu antara awal pengujian sampai dengan akhir dari interval tertentu suatu pengamatan

\section{b. Persentase Kecambah}

Persentase kecambah menunjukkan jumlah kecambah normal yang dihasilkan oleh benih pada kondisi lingkungan tertentu dalam jangka waktu yang telah ditetapkan. Presentase kecambah dihitung pada saat berumur 60 hss. Menurut Sutopo (2012) cara menghitung persentase perkecambahan yaitu sebagai berikut:

$$
\mathrm{PK}=\frac{\text { Jumlah biji yang berkecambah }}{\text { jumlah benih yang diuji }} \times 100 \%
$$

Keterangan :

PK = Persentase kecambahan

c. Indeks Vigor

Indeks vigor dihitung dengan menghitung hari yang diperlukan untuk berkecambah dengan banyaknya jumlah benih yang berkecambah. Menurut sutopo (2012) indeks vigor dihitung dengan menggunakan rumus dibawah ini :

$$
\mathrm{IV}=\frac{\mathrm{G} 1}{\mathrm{D} 1}+\frac{\mathrm{G} 2}{\mathrm{D} 2}+\frac{\mathrm{G} 3}{\mathrm{D} 3} \ldots . \frac{\mathrm{Gn}}{\mathrm{Dn}}
$$


Keterangan :

IV $=$ Indeks Vigor

$\mathrm{G} \quad=$ Jumlah benih yang berkecambah pada hari tertentu

D = Waktu yang bersesuaian dengan jumlah tersebut

$\mathrm{N} \quad=$ Jumlah hari pada perhitungan terakhir

d. Panjang Axis Embrio (cm)

Panjang calon akar (radikula) diukur dari leher akar sampai ujung akar, pengukuran dilakukan pada saat tanaman berumur 60 hss.

\section{Analisis Data}

Data yang diperoleh dari hasil penelitian dianalisis ragam pada taraf $5 \%$ dan bila terdapat pengaruh yang nyata dilanjutkan dengan uji Beda Nyata Terkecil (BNT) pada taraf $5 \%$.

\section{Hasil dan Pembahasan}

Hasil penelitian dapat dilihat pada rekapitulasi data pada tabel 1.

Tabel 1. Hasil pengamatan perkecambahan terhadap perendaman larutan kimia

\begin{tabular}{ccccc}
\hline Perlakuan & $\begin{array}{c}\text { Laju } \\
\text { Perkecambahan }\end{array}$ & $\begin{array}{c}\text { Persentase } \\
\text { kecambah }\end{array}$ & Indeks vigor & Panjang Axis \\
\hline $\mathrm{p}_{0}$ & $57,00 \mathrm{~d}$ & $36,00 \mathrm{~b}$ & $0,046 \mathrm{~b}$ & $1,6 \mathrm{~b}$ \\
$\mathrm{p}_{1}$ & $49,90 \mathrm{c}$ & $50,00 \mathrm{~cd}$ & $0,142 \mathrm{c}$ & $3,3 \mathrm{c}$ \\
$\mathrm{p}_{2}$ & $43,00 \mathrm{c}$ & $56,00 \mathrm{~d}$ & $0,159 \mathrm{c}$ & $3,2 \mathrm{c}$ \\
$\mathrm{p}_{3}$ & $37,33 \mathrm{~b}$ & $67,00 \mathrm{e}$ & $0,155 \mathrm{c}$ & $7,00 \mathrm{~d}$ \\
$\mathrm{p}_{4}$ & $36,00 \mathrm{~b}$ & $78,33 \mathrm{e}$ & $0,161 \mathrm{c}$ & $5,80 \mathrm{~d}$ \\
$\mathrm{p}_{5}$ & $50,67 \mathrm{~cd}$ & $40,00 \mathrm{c}$ & $0,050 \mathrm{~b}$ & $1,20 \mathrm{ab}$ \\
\hline
\end{tabular}

\section{Laju Perkecambahan (Hari)}

Hasil sidik ragam menunjukkan bahwa perlakuan perendaman dalam larutan atonik berbeda sangat nyata terhadap laju perkecambahan benih aren. Hasil pengamatan laju perkecambahan dapat dilihat pada histogram 1 di bawah ini.

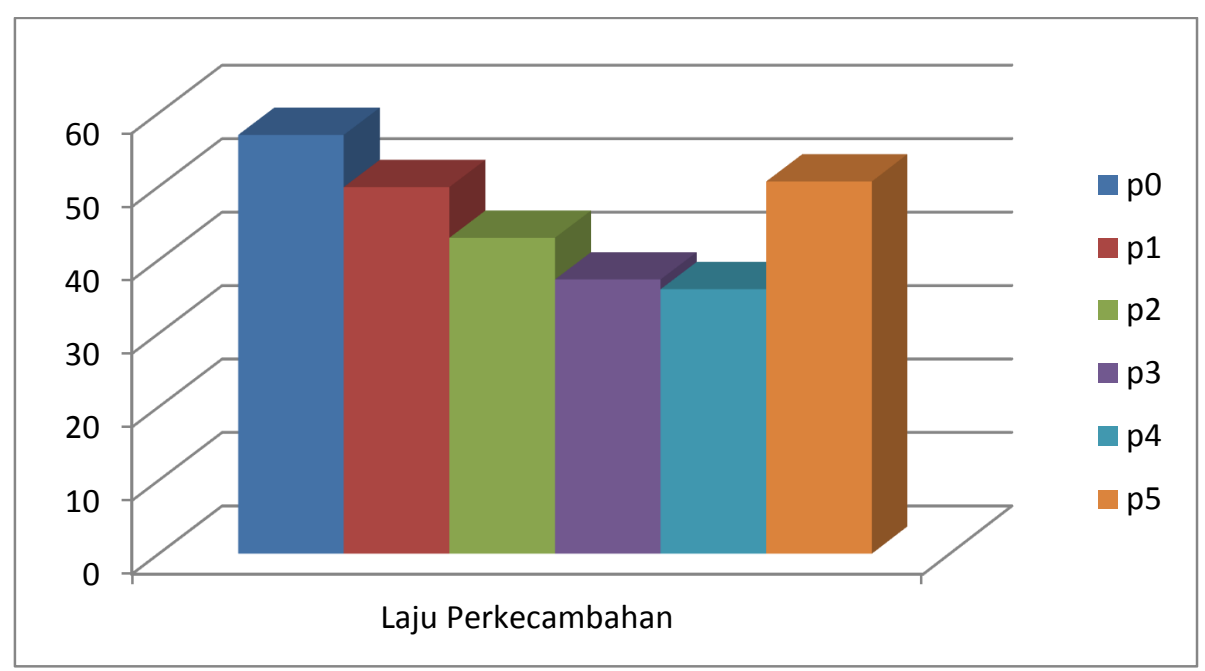

Gambar 1. Histogram laju perkecambahan (hari) biji aren 
Berdasarkan hasil uji BNT taraf $5 \%$ pengaruh lama perendaman dalam larutan atonik terhadap laju perkecambahan biji aren menunjukkan bahwa perlakuan Perlakuan p4 tidak berbeda nyata dengan perlakuan p3, tetapi berbeda nyata dengan perlakuan lainnya.

Berdasarkan hasil pengamatan bahwa perlakuan p3 (perendaman 15 menit) dan perlakuan p4 (perendaman 20 menit) menunjukkan laju perkecambahan yang tercepat yaitu 37,33 hari dan 36,00 hari, sedangkan perlakuan $\mathrm{p} 0$ (tanpa perendaman) menunjukkan waktu laju perkecambahan yang terlama yaitu 57,00 hari dan perlakuan p6 menunjukkan biji yang tidak berkecambah.

Waktu yang dibutuhkan untuk kemunculan radikula dan plumula pada benih aren dipengaruhi oleh kemampuan benih menyerap air, kemampuan embrio untuk keluar dan berkecambah serta perendaman yang tepat pada larutan kimia.

Biji aren memiliki masa dormansi yang panjang. Hal ini disebabkan struktur kulit benih yang tebal. Salah satu cara untuk mematahkan dormansi benih aren adalah dengan merendamkan benih dalam larutan kimia seperti larutan atonik yang mengandung hormon auksin. Perendaman dengan atonik dapat membantu air masuk kedalam biji dan embrio dapat keluar dan berkecambah. Hal ini sesuai dengan pendapat Hedty et al (2014), yang menyatakan secara kimia pemecahan dormansi dapat dilakukan dengan cara merendamkan benih pada larutan asam dengan waktu perendaman yang berbeda tergantung pada bentuk benih. Ali et al (2011) dalam Setya dkk (2015) menambahkan bahwa mekanisme perkecambahan biji yang dipengaruhi oleh larutan kimia adalah karena kemampuan larutan kimia untuk memecah kulit biji yang mengarah ke penyerapan air dan imbibisi benih.

\section{Persentase Kecambah (\%)}

Hasil sidik ragam menunjukkan bahwa perlakuan perendaman dalam larutan atonik berbeda sangat nyata terhadap persentase kecambah benih aren. Hasil pengamatan ratarata persentase kecambah dapat dilihat pada histogram 2 di bawah ini.

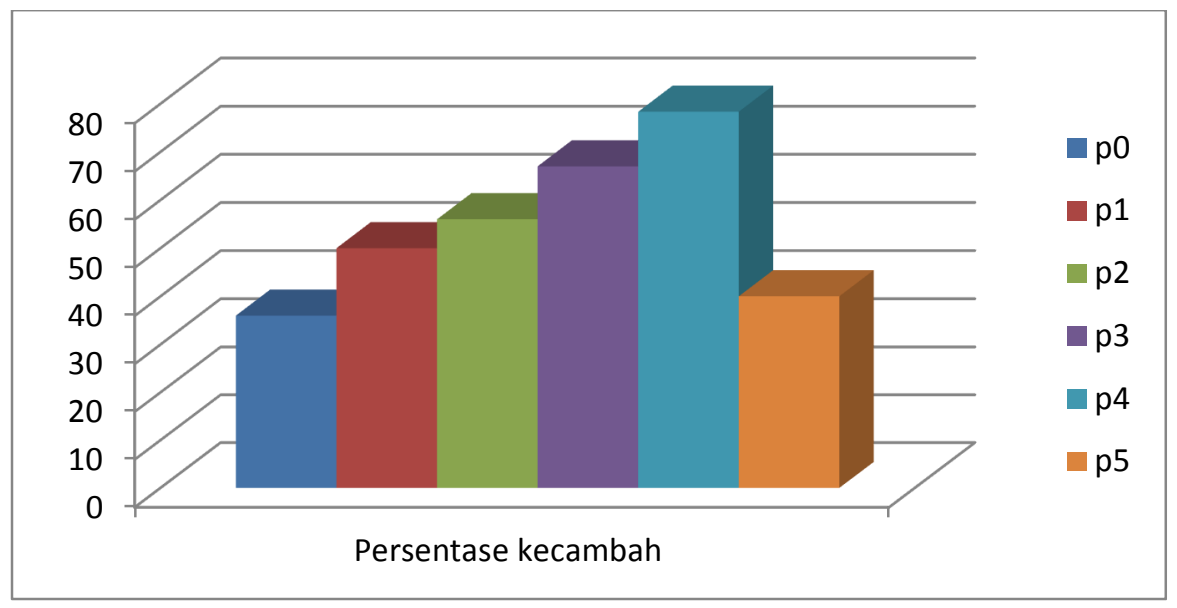

Gambar 2. Histogram persentase kecambah (\%) biji aren 
Berdasarkan hasil uji BNT 5\% pengaruh lama perendaman dalam larutan atonik menunjukkan bahwa perlakuan p4 tidak berbeda nyata dengan perlakuan p3, tetapi berbeda nyata dengan perlakuan lainnya. Persentase kecambah tertinggi pada perlakuan p4 (perendaman 20 menit) yaitu 78,33\%, sedangkan yang terendah diperoleh pada perlakuan p0 (tanpa perendaman) yaitu 36,00 \% dan perlakuan p6 menunjukkan benih yang tidak tumbuh.

Hasil penelitian perlakuan p2 (perendaman 20 menit) memberikan hasil yang terbaik. Hal ini disebabkan perendaman benih dalam larutan kimia menyebabkan kulit benih menjadi lunak, air dan gas dapat berdifusi masuk dan senyawa-senyawa inhibtor perkecambahan seperti fluoride dan kaumarin larut kedalam larutan kimia selama proses perendaman (Salisbury dan Ross, 1995 dalam Suyatmi, 2008).

Perlakuan perendaman dalam larutan atonik mempermudah masuknya air dan gas kedalam biji sehingga memberikan perkecambahan yang baik. Sesuai dengan pernyataan Oben dkk (2014), yang menyatakan bahwa perlakuan terhadap benih memberikan kecepatan tumbuh yang baik, karena air dan oksigen yang dibutuhkan untuk perkecambahan dapat masuk kedalam benih tanpa halangan sehingga benih dapat berkecambah. Selain itu menurut Suseno (1974) dalam Nugroho dan Salamah (2015), bahwa persentase perkecambahan yang tinggi terjadi metabolisme sel-sel embrio setelah menyerap air yang didalamnya berlangsung reaksi perombakan yang biasa disebut katabolisme dan sintesa komponen-komponen sel untuk pertumbuhan atau yang dikenal dengan anabolisme. Proses metabolisme ini berlangsung terus dan merupakan pendukung dari pertumbuhan kecambah hingga dewasa.

\section{Indeks Vigor}

Hasil sidik ragam menunjukkan bahwa perlakuan perendaman dengan larutan atonik berbeda nyata terhadap indeks vigor benih aren. Hasil pengamatan rata-rata indeks vigor dapat dilihat pada histogram 3 di bawah ini.

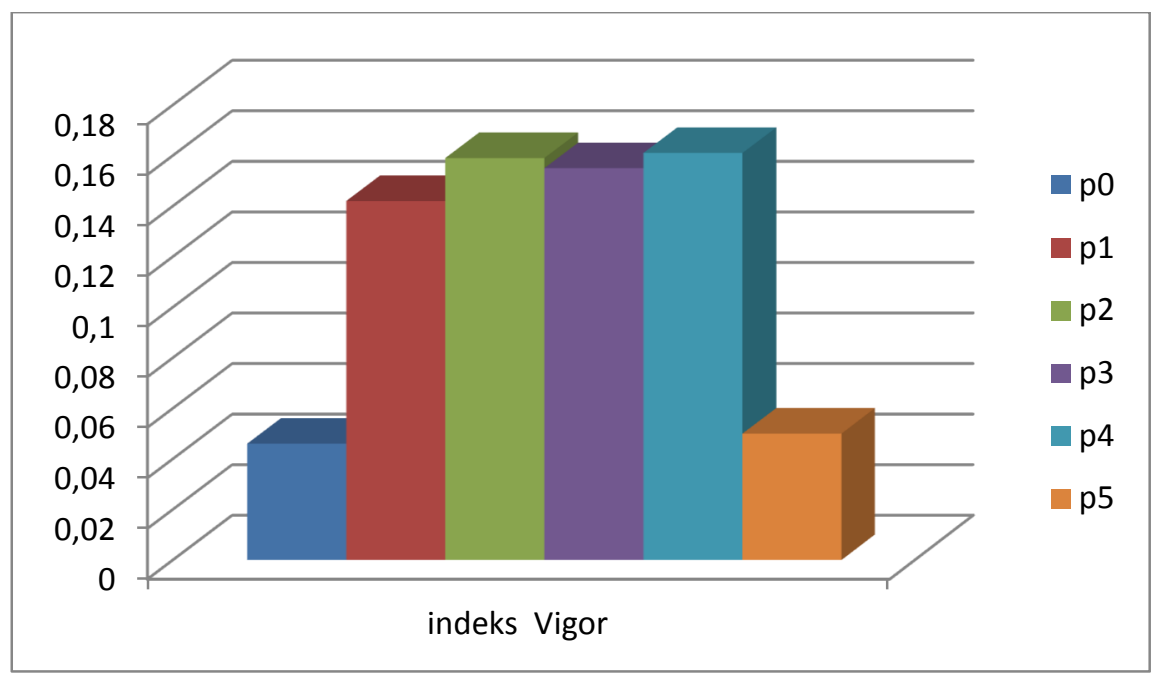

Gambar 3. Histogram indeks vigor biji aren 
Berdasarkan hasil uji BNT 5\% pengaruh lama perendaman dalam larutan atonik terhadap rata-rata indeks vigor menunjukkan bahwa p4 tidak berbeda nyata dengan perlakuan p1, p2, dan p3, tetapi berbeda nyata dengan perlakuan p0 dan p5.

Perlakuan p4 (perendaman 20 menit) menunjukan hasil yang tertinggi yaitu 0,161 sedangkan perlakuan p0 (tanpa perendaman) menunjukkan hasil yang terendah yaitu 0,046. Hasil penelitian perlakuan p2 (perendaman 20 menit) memberikan hasil yang terbaik. Indeks vigor sendiri berhubungan erat dengan kecepatan tumbuh benih (hari berkecambah) yang mana kecepatan tumbuh akan berbanding lurus dengan indeks vigor benih. Hal ini sesuai dengan literatur Kartasapoetra (2004), indeks vigor berhubungan erat dengan kecepatan berkecambah dari suatu kelompok benih. Indeks vigor yang tinggi menunjukkan kecepatan berkecambah benih juga tinggi dan lebih tahan hidup terhadap keadaan lingkungan yang kurang menguntungkan.

Benih aren yang mendapatkan perlakuan asam sulfat dapat segera berkecambah. Nilai indeks vigor tertinggi adalah pada perlakuan p2 (perendaman 20 menit) yaitu 0,159. Nilai kecepatan berkecambah dan indeks vigor menunjukkan kondisi benih apakah memiliki vigor tinggi atau rendah. Semakin tinggi nilai indeks vigor, maka semakin tinggi vigor tersebut dan benih semakin cepat perkecambahannya (Sutopo, 2012).

Perlakuan p0 (tanpa perendaman) menunjukkan hasil penelitian terendah pada semua parameter. Hal ini dikarena pada perlakuan p0 tidak dilakukan upaya pematahan dormansi secara kimia sehingga tidak mengalami kelunakan pada bagian kulit benihnya sehingga kulit benih aren tetap kedap air dan oksigen. Kondisi kulit benih yang kedap tersebut dapat menghambat atau memperlambat proses perkecambahan, karena tahap awal dan proses perkecambahan adalah peristiwa imbibisi air atau proses masuknya air kedalam biji. Sebagaimana menurut Sutopo (2012), bahwa tahapan pertama suatu perkecambahan benih dimulai dengan proses penyerapan air oleh benih.

\section{Panjang Axis Embrio (cm)}

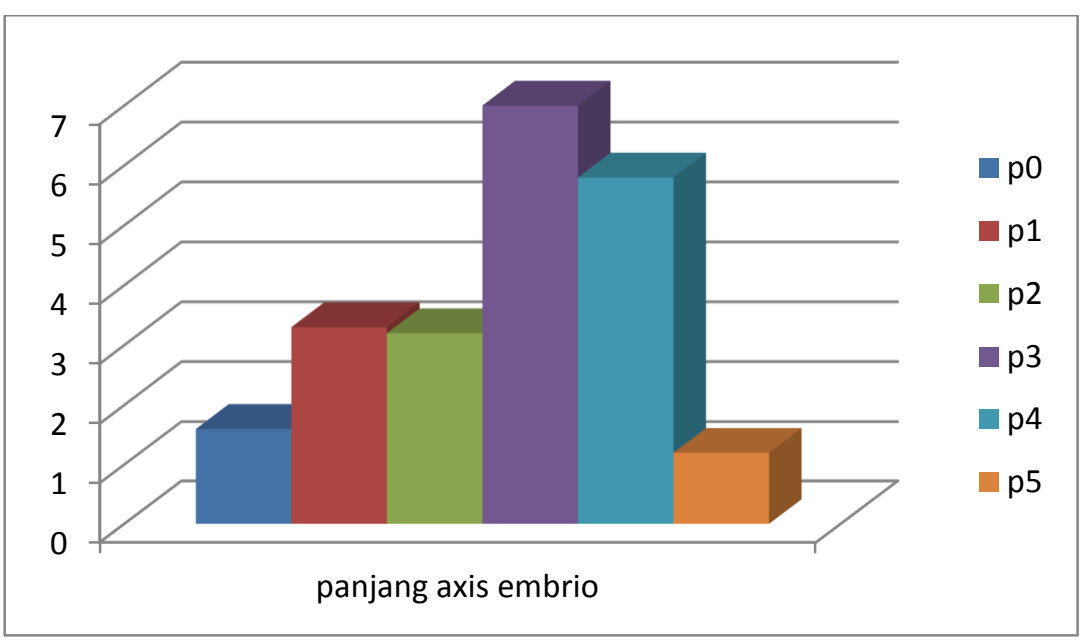

Gambar 4. Histogram panjang axis embrio biji aren 
Hasil sidik ragam menunjukkan bahwa perlakuan perendaman dengan larutan atonik berbeda sangat nyata terhadap panjang axis embrio benih aren. Hasil pengamatan rata-rata panjang axis embrio dapat dilihat pada Gambar 4.

Berdasarkan hasil uji BNT 5\% pengaruh lama perendaman dalam larutan atonik menunjukkan bahwa perlakuan p0 tidak berbeda nyata dengan perlakuan p5, tetapi berbeda nyata dengan perlakuan lainnya. Perlakuan p1 tidak berbeda nyata dengan perlakuan p2, tetap berbeda nyata dengan perlakuan lainnya. Perlakuan p3 tidak berbeda nyata dengan perlakuan $\mathrm{p} 4$, tetapi berbeda nyata dengan perlakuan p5 dan p6. Perlakuan p4 berbeda nyata dengan perlakuan p5.

Hasil penelitian menunjukkan perlakuan p3 (perendaman 15 menit) yang memiliki panjang axs embrio yang terbaik yaitu $7,00 \mathrm{~cm}$, dan yang paling pendek pada perlakuan $\mathrm{p} 0$ (tanpa perendaman) yaitu $1,60 \mathrm{~cm}$ dan perlakuan p6 menunjukkan benih yang tidak tumbuh. Proses perkecambahan benih aren sangat menarik tidak seperti pada tanaman monokotil umumnya. Perkecambahan benih aren dimulai dengan munculnya axis embrio. Setelah mencapai panjang tertentu axis embrio membengkak pada bagian ujungnya. Pada bagian inilah akan muncul plumula dan akar (Marsono. 1989 dalam Rofik, Aenur dan Endan Murniati, 2008).

\section{Kesimpulan}

Kesimpulan dari penelitian ini adalah bahwa, perlakuan lama perendaman dalam larutan atonik memberikan pengaruh yang sangat nyata terhadap parameter laju perkecambahan, persentase kecambah dan panjang axis embrio, tetapi menunjukkan berbeda nyata terhadap parameter indeks vigor. Perlakuan $\mathrm{p}_{4}$ (perendaman selama 20 menit) menunjukkan hasil yang terbaik yaitu laju perkecambahan sebesar 36,00 hari, persentase perkecambahan sebesar 78,33\% dan indeks vigor sebesar 0,161.

\section{Daftar Pustaka}

Ali H. H., H. Tanveer, M. A. Nadeem, and H. N. Asghar. (2011). Scientific Note: Methods to Break Seed Dormancy of Rhynchosia capitata a Summer Annual Weed. J. Chilean Journal Of Agricultural Research 71(3).

Effendi, D.S., 2010. Prospek Pengembangan Tanaman Aren (Arenga pinnata Merr) Mendukung Kebutuhan Bioetanol di Indonesia. Pusat Penelitian dan Pengembangan Perkebunan. Perspektif (9)1: hal $36-46$.

Farida, 2014. Pengaruh skarifikasi dan $\mathrm{H}_{2} \mathrm{SO}_{4}$ terhadap perkecambahan dan pertumbuhan bibit dengan beberapa posisi buah pada tandan aren (Arenga Pinnata Merr). Tesis. Program magister pertanian program studi pertanian Tropika Basah. Fakultas pertanian. Universitas mulawarman.

2017. Pengaruh Lama Perendaman Dalam Giberelin $\left(\mathrm{GA}_{3}\right)$ Terhadap Perkecambahan Benih Aren (Arenga pinnata Merr). Magrobis Journal (17)1 April 2017. 
Hedty, Mukarlina, dan Masnur T. 2014. Pemberian H2SO4 dan Air Kelapa pada Uji Viabilitas Biji Kopi Arabika (Coffea arabika L.) J. Protobiont, 3(1): 7-11.

Hanafiah, K.A. 2010. Rancangan Percobaan Teori dan Aplikasi. PT. Rajagrafindo Persada. Jakarta.

Kartasapoetra A.G. 2003. Teknologi Benih Pengolahan Benih dan Tuntunan Praktikum. Rineka Cipta. Jakarta.

Mashud N.R Rahman dan R. B. Mallangkay. 1989. Pengaruh berbagai perlakuan fisik dan kimia terhadap perkecambahan dan pertumbuhan bibit aren (Arenga pinnata (Wurmb.) Merr). Jurnal penelitian kelapa 4(1): $27-37$.

Marsono. 1989. Perkecambahan Benih Aren. Duta Rimba. No.105-106/XV/ 1989. Pusat Penelitian dan Pengembangan Tanaman Hutan. Bogor

Nugroho, Triyanto Adi dan Zuchrotus Salamah 2015. Pengaruh lama perendaman dan konsentrasi Asam Sulfat $\left(\mathrm{H}_{2} \mathrm{SO}_{4}\right)$ terhadap perkecambahan Biji Sengon Laut. JUPEMASI (2)1:hal. 230-236.

Oben, Bintoro., dan Riniarti, Melya. "Pengaruh Perendaman Benih pada Berbagai Suhu Awal Air terhadap Viabilitas Benih Kayu Afrika (Maesopsis eminii)". Jurnal Sylva Lestari (2)1:101-108.

Puslitbang Bioteknologi. 2000. Study on in vitro and in vivo seed germination of Arenga pinnata (Wurmb) Merr.; Studi perkecambahan biji aren (Arenga pinnata (Wurmb) Merr.) secara in vitro dan in vivo. Bogor.

Rofik A., E. Murniati. 2008. Pengaruh perlakuan deoperkulasi benih dan media perkecambahan untuk meningkatkan viabilitas benih aren (Arenga pinnata (Wurmb.) Merr.). Bul. Agron. 36(1):33-40.

Saleh M S. 2003. Perlakuan Fisik dan Konsentrasi Kalium Nitrat untuk mempercepat perkecambahan benih aren. Buletin Agroland 10(4) : 346-351.

Salisbury, F.B. dan C.W. Ross, 1995, Fisiologi Tumbuhan, diterjemahkan oleh Diah R Lukman, Penerbit ITB, Bandung.

Soeseno, S. 2000. Bertanam Aren. Penebar Swadaya, Jakarta. Hal 63.

Sutopo, L. 2012. Teknologi Benih. Rajawali Press Jakarta.

Suyatmi, Endah Dwi H, Sri Darmanti. 2008. Pengaruh Lama Perendaman dan Konsentrasi Asam Sulfat (H2SO4) terhadap Perkecambahan Benih Jati (Tectona grandis Linn.f). Jurnal Departemen Kehutanan : 28-36.

Wirawan, B. dan S. Wahyuni. 2002. Memprodusi Benih Bersertifikat. Penebar Swadaya. Jakarta. 